\title{
Functional characteristics of a braided river in the Qinghai-Tibet Plateau, China
}

\author{
Peng $\mathrm{Gao}^{1}$, Zhiwei $\mathrm{Li}^{2}$, Yuchi $\mathrm{You}^{3}$, Yinjun Zhou ${ }^{4}$, and Hervé Piégay ${ }^{5}$ \\ ${ }^{1}$ Syracuse University \\ ${ }^{2}$ Wuhan University \\ ${ }^{3}$ Changsha University of Science \& Technology \\ ${ }^{4}$ Changjiang River Scientific Research Institute \\ ${ }^{5} \mathrm{CNRS}$
}

July 2, 2020

\begin{abstract}
In this study, we unveiled the lumped effects at the reach spatial scale over three decades in one of the braided rivers in the Qinghai-Tibet Plateau of China, the Upper Lancang River (ULR). Using Landsat images obtained in 13 years between 1989 and 2018, we extracted flowing and non-flowing channels, active channel widths (unvegetated bars and flowing channels), and calculated lateral shifting rates of the main channel for the 13 periods. We also developed an empirical equation between vegetation area $(\mathrm{Av})$ calculated from the high-resolution ortho-photo derived from an Unmanned Aerial Vehicle survey and Normalized Difference Vegetation Index for pixels of the Landsat image obtained at the same time. This relationship allowed us to estimate Av for other 12 selected years. We found that (1) braiding intensity increases with low discharges, indicating that the ULR is a very well-connected braided system with groundwater providing a large set of aquatic habitats, (2) this braided system is very well-supplied and actively shifting in relation to peak flow and flood duration, and (3) The ULR supports a progressive vegetation encroachment, which seems to be linked to temperature rising. Our study showed several similar morphological patterns to those in other braided rivers, such as the ones observed in the European Alps but much more active, well-supplied and highly connected. These similarities suggest that similar morphodynamic processes might take effect in the braided rivers with very high elevations and potentially high spots of biodiversity, indicating the ULR may be a reference for this region similarly to the Tagliamento in the Alps, but it seems that this system can be very sensitive to global change due to vegetation encroachment following temperature rising and decreases of low flows.
\end{abstract}

\section{Hosted file}

Lancang River submission.docx available at https://authorea.com/users/339150/articles/465400functional-characteristics-of-a-braided-river-in-the-qinghai-tibet-plateau-china

\section{Hosted file}

Table 1.docx available at https://authorea.com/users/339150/articles/465400-functionalcharacteristics-of-a-braided-river-in-the-qinghai-tibet-plateau-china 

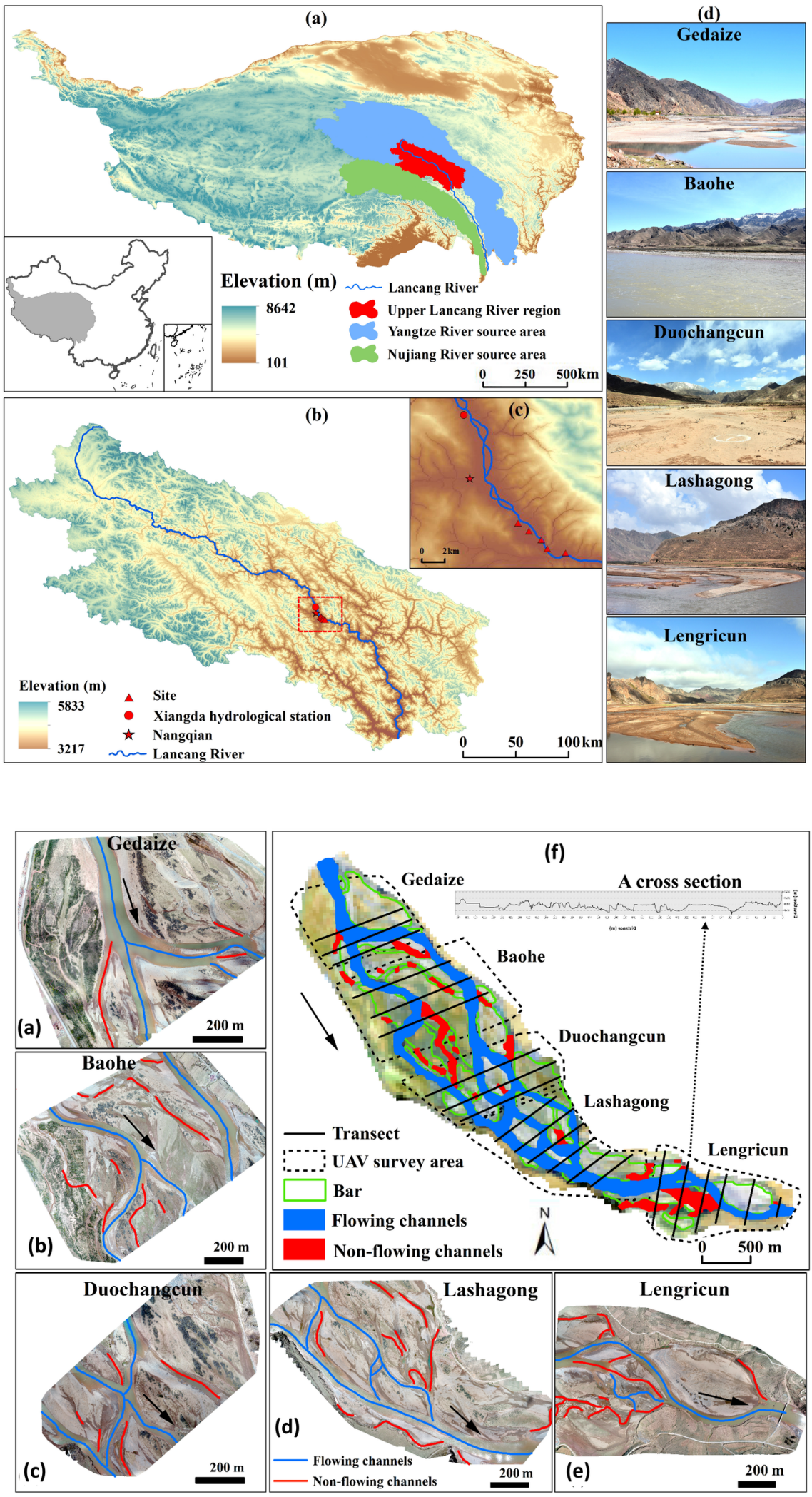

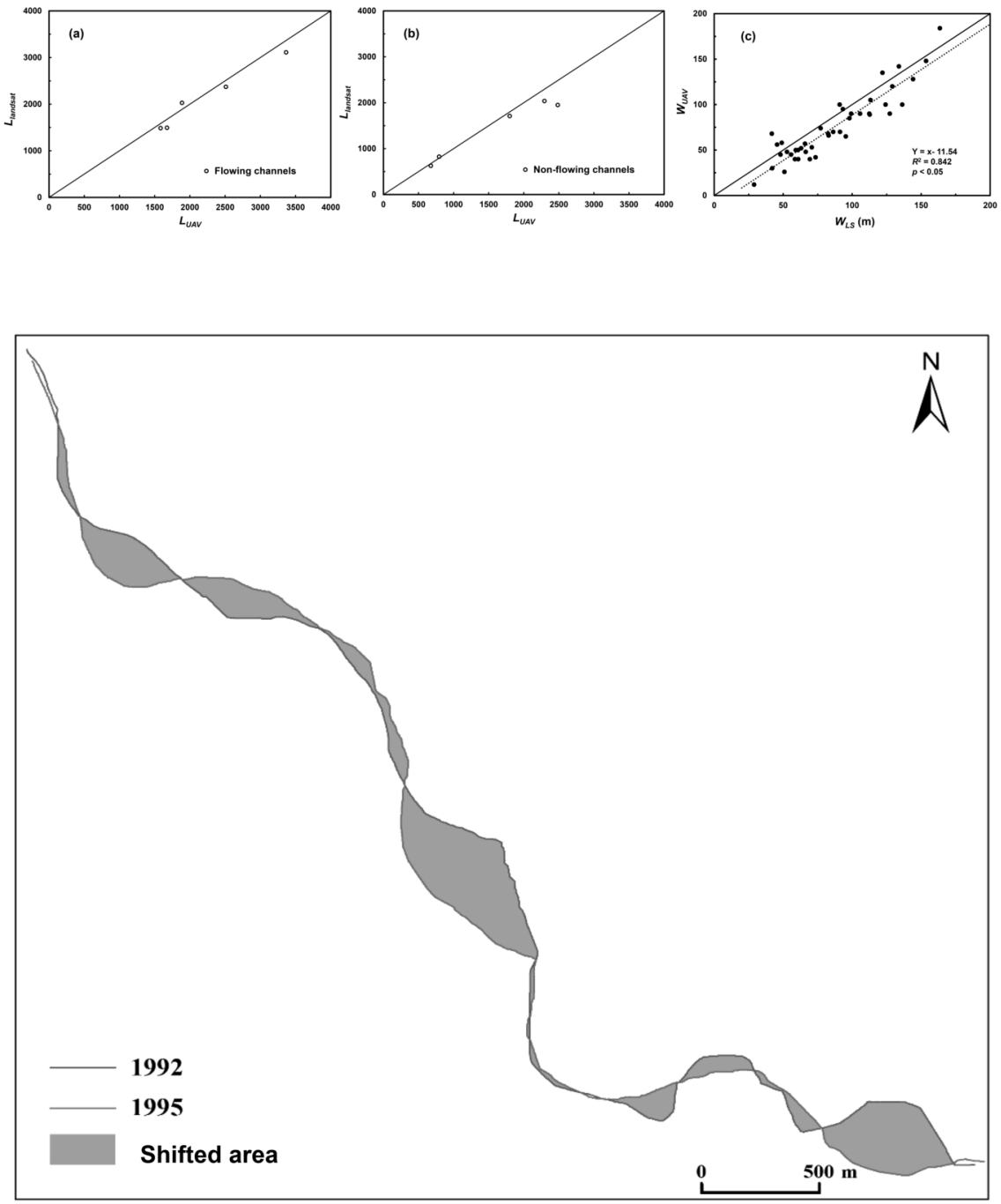

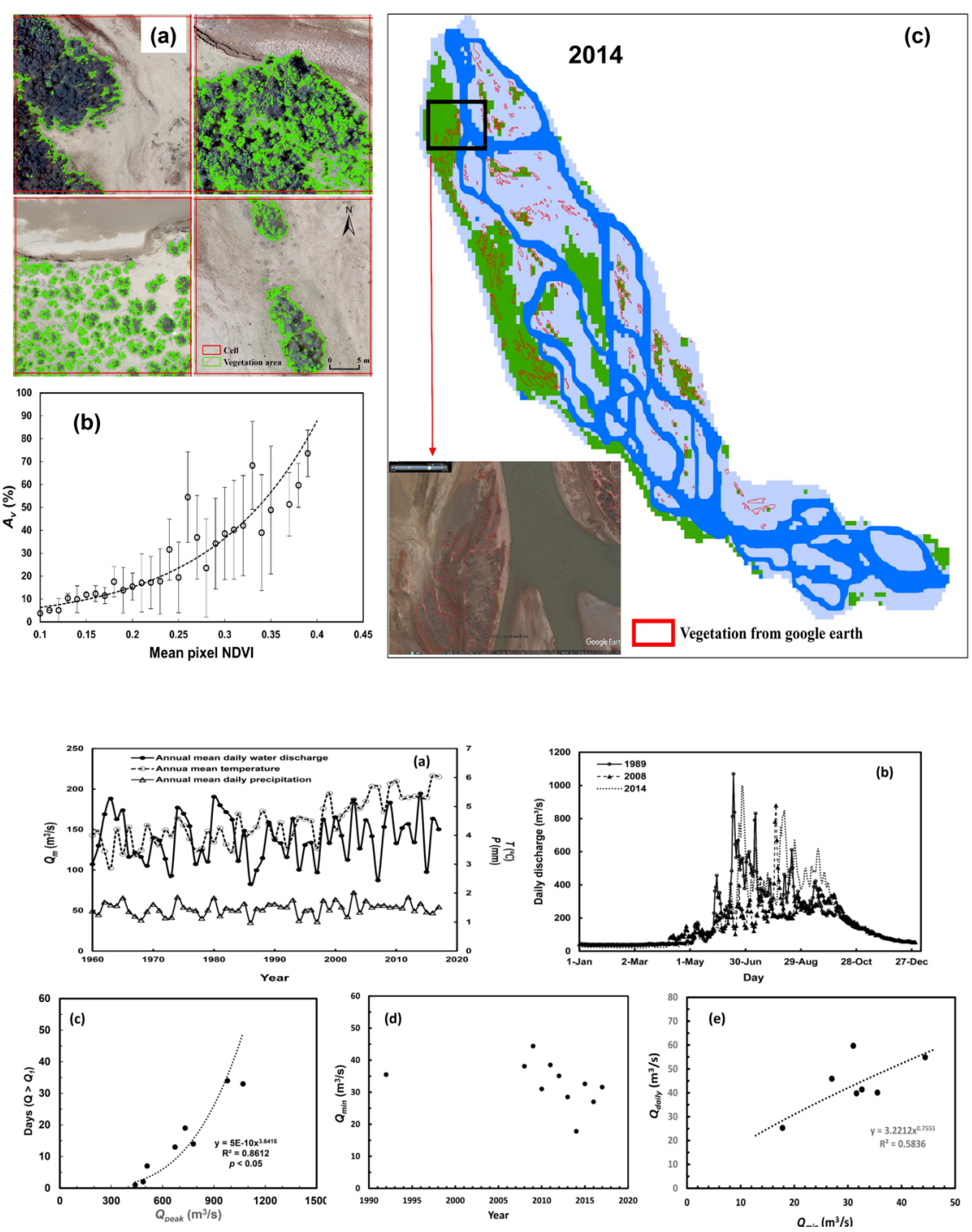

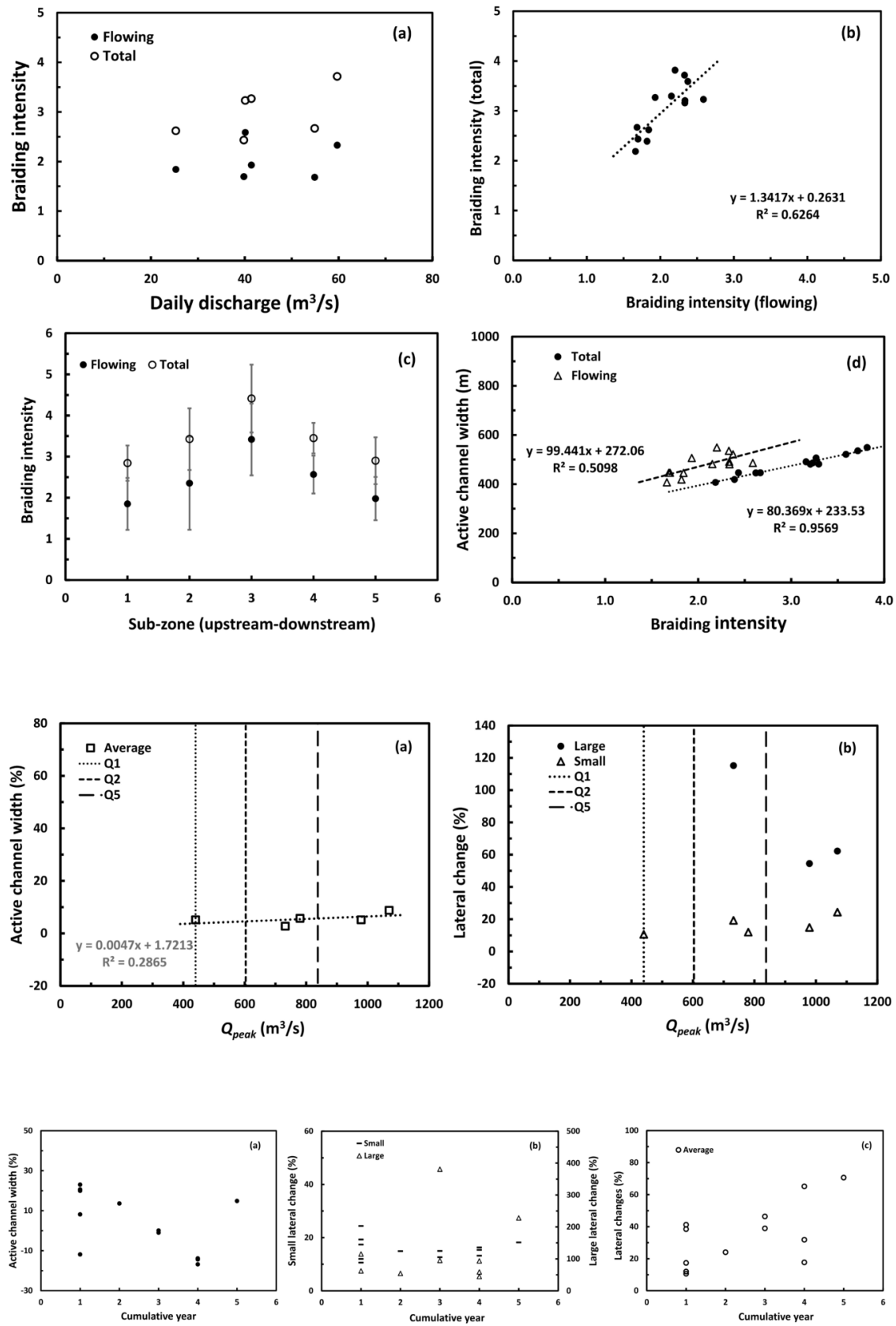

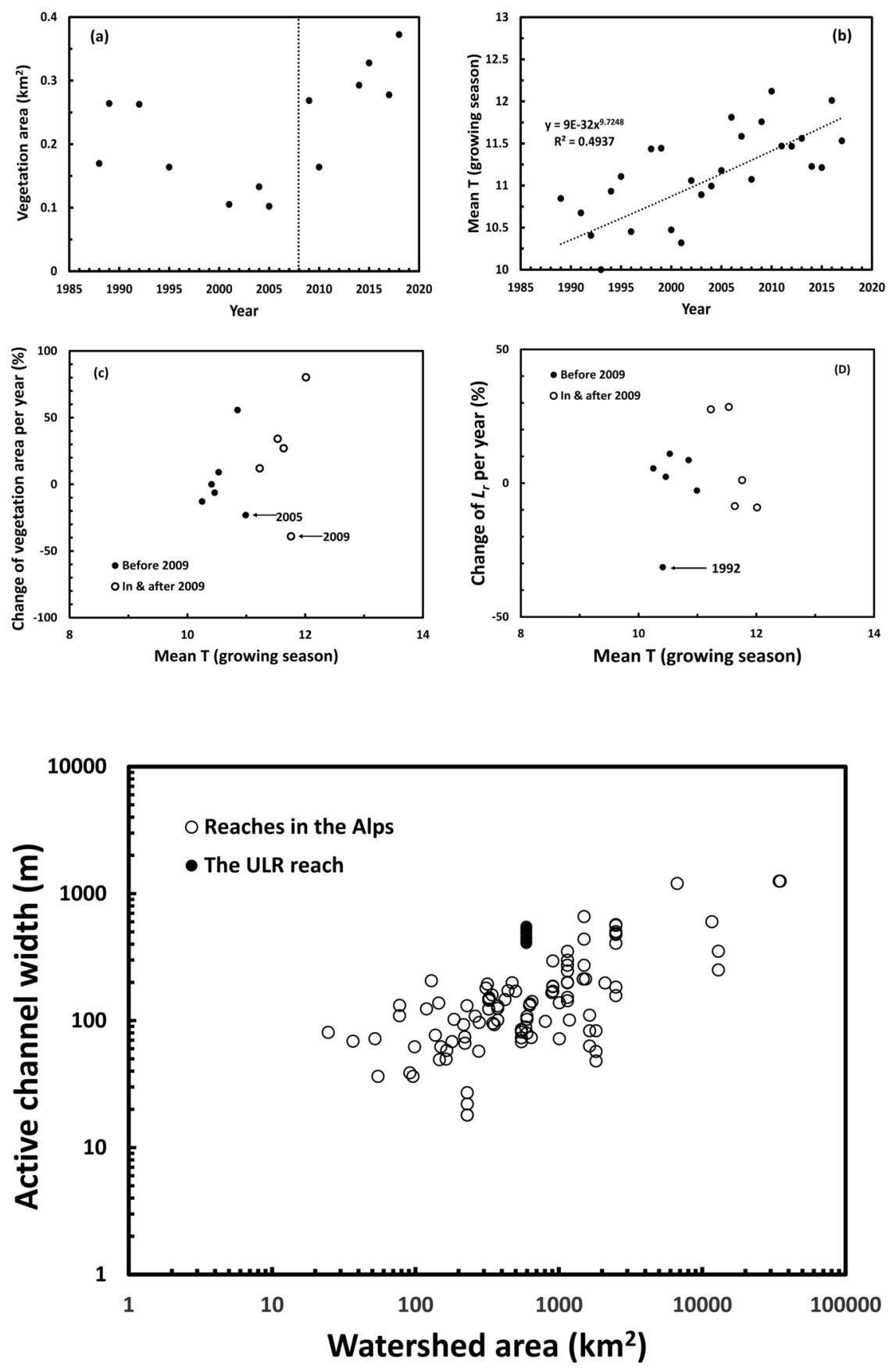


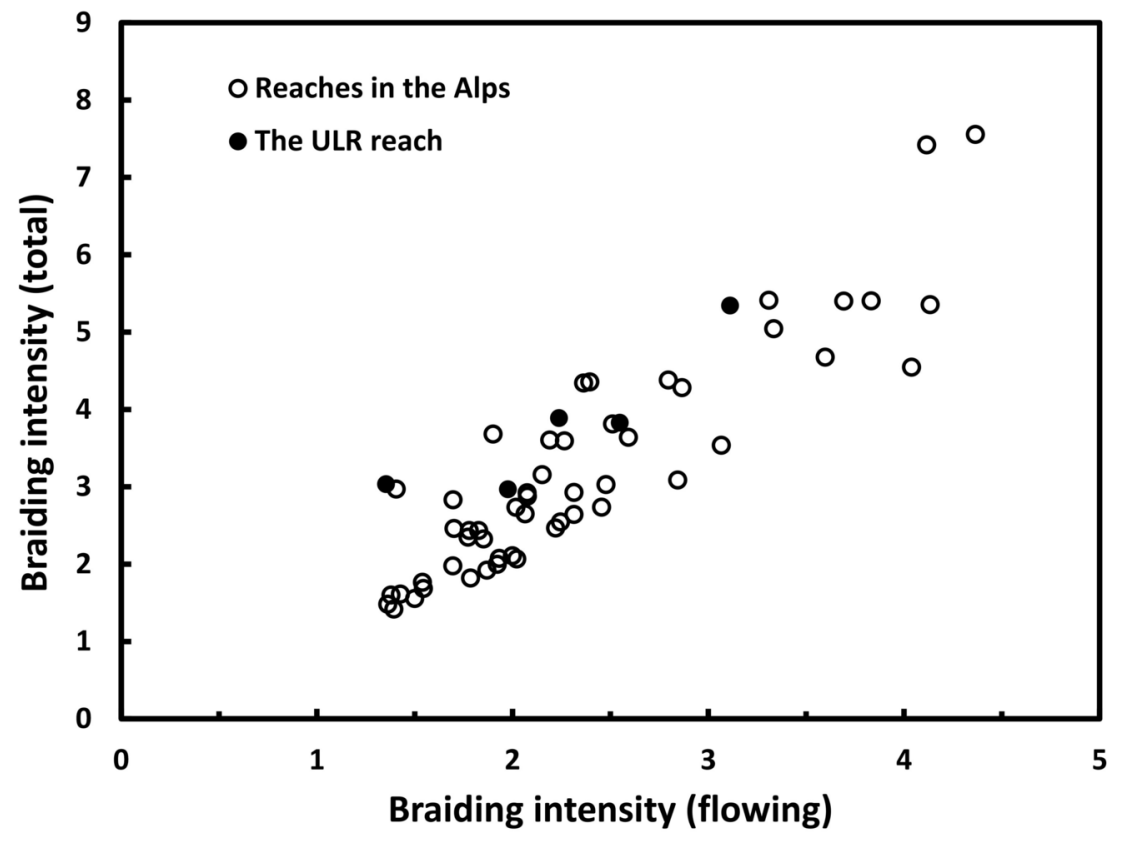

